Portland State University

PDXScholar

Spring 5-14-2015

\title{
Combining Systems Methodologies to Reduce Allergen-Related Food Recalls
}

Jill Marie Sweney

Portland State University

Follow this and additional works at: https://pdxscholar.library.pdx.edu/open_access_etds

Part of the Business Commons, and the Food Processing Commons Let us know how access to this document benefits you.

\section{Recommended Citation}

Sweney, Jill Marie, "Combining Systems Methodologies to Reduce Allergen-Related Food Recalls" (2015). Dissertations and Theses. Paper 2373.

https://doi.org/10.15760/etd.2370

This Thesis is brought to you for free and open access. It has been accepted for inclusion in Dissertations and Theses by an authorized administrator of PDXScholar. For more information, please contact pdxscholar@pdx.edu. 
Combining Systems Methodologies to Reduce Allergen-Related Food Recalls

by

Jill Marie Sweney

A thesis submitted in partial fulfillment of the requirements for the degree of

Master of Science

in

Systems Science

Thesis Committee:

Wayne Wakeland, Chair

Michele Gamburd

Madeleine Pullman

Portland State University

2015 
Copyright (C) 2015 by Jill Marie Sweney 


\begin{abstract}
The risk of poor food safety is a major focus for managers in the food manufacturing industry. Despite industry-led and regulatory efforts to improve the overall food safety of US packaged consumer foods, product recalls and market withdrawals are increasing. This is especially true for the most frequent cause for food recall: the undeclared allergen. With industry trends leaning toward adoption of third-party food safety management certifications, a popular food safety code from the Safe Quality Foods Institute is evaluated using Systems Analysis. Three changes to the food safety code are proposed to address three of the top causes for an allergen-related recall in the United States. In practice, the SQF code should make better use of control theory to reduce delays in production monitoring activities, should make better use of purposeful action in the implementation of a HACCP plan to ensure continuing validity of the plan, and SQFI needs to consider adding an organizational assessment for food safety culture.
\end{abstract}




\section{TABLE OF CONTENTS}

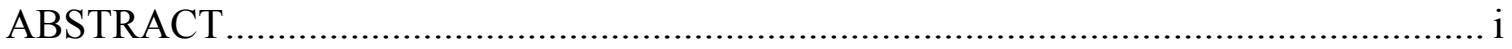

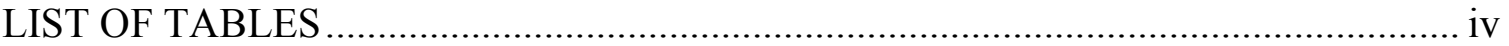

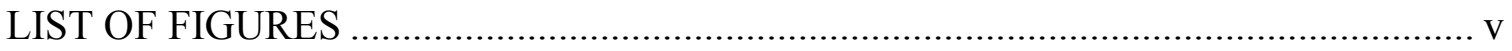



1.1 The Food Safety Problem............................................................................... 1

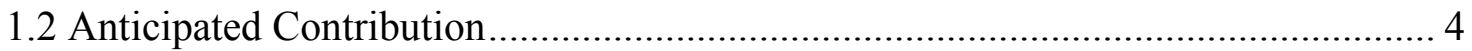

1.3 Research Question..................................................................................... 5

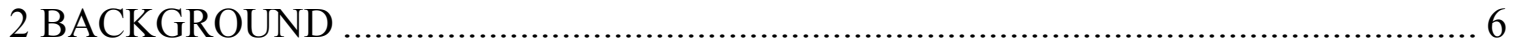

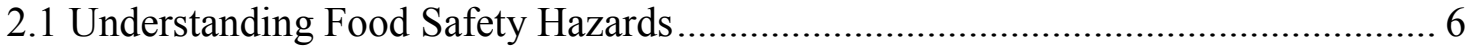

2.2 Quality Management in Food Manufacturing ......................................................... 8

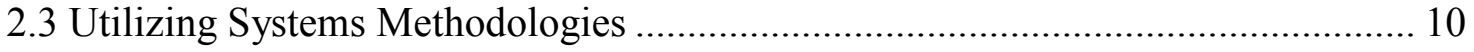

2.3.1 Example of Total Systems Intervention …………......................................... 11

2.3.2 Example of Mixing Two Systems Approaches ................................................. 12

2.4 A Gap in the Literature: Applying Systems Methodologies to Food Safety .......... 14

2.4.1 Systems Methodologies in Food Safety Adjacent Systems............................... 14

2.4.2 Conceptual Models of the Food Manufacturing System .................................. 15

2.5 Background Summary ............................................................................. 18

3 METHODS …………………… 19

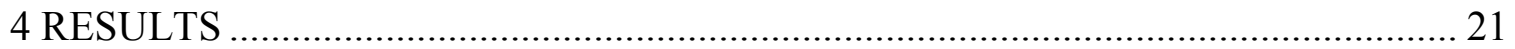

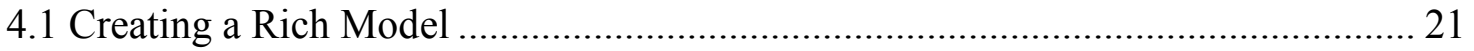

4.1.1 The Viewpoint in the SQF Code ………………................................... 22

4.1.2 Identifying Complexity in Food Manufacturing and Food Safety .................. 28

4.2 Systems Analysis of the Allergen-Related Recall ................................................ 31

4.2.1 Proactive Use of Feedback in Critical Control Points..................................... 32

4.2.1.1 Case Study: Verification Activities in Parallel with Production .................... 37

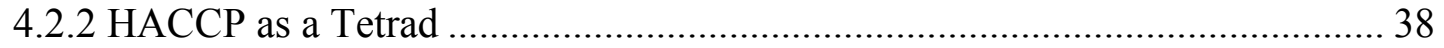

4.2.2.1 Case Study: Reviewing Ingredient Formulations .......................................... 41

4.2.3 Harmonious Organizational Hierarchy........................................................ 42

4.2.3.1 Case Study: Creating a Culture of Caution and Care in Allergen Handling . 45

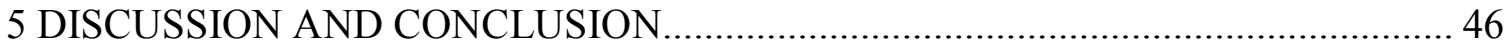

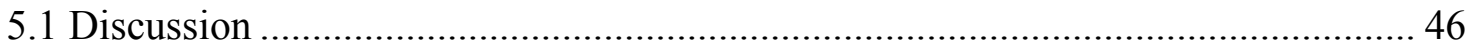


5.2 Limitations ....

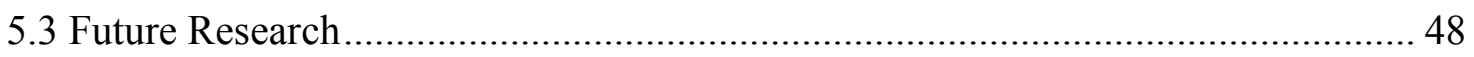

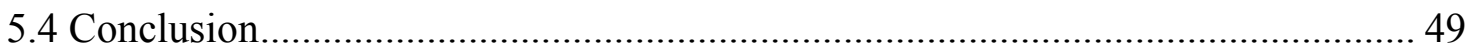

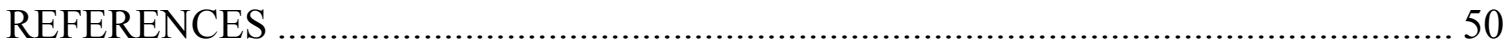




\section{LIST OF TABLES}

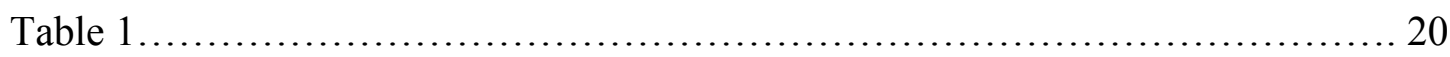

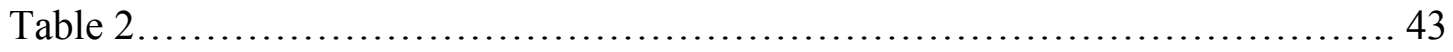




\section{LIST OF FIGURES}



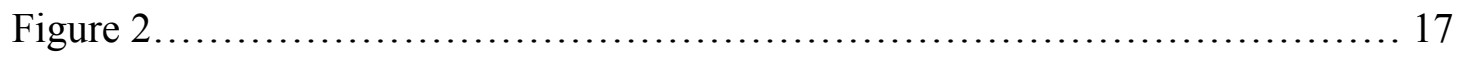





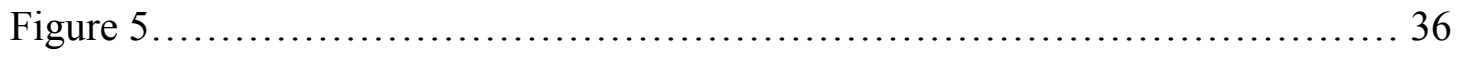



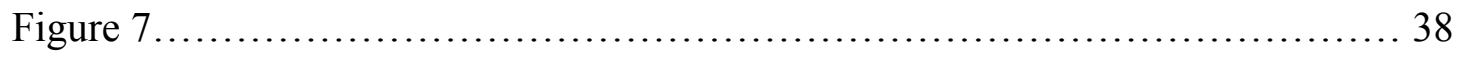



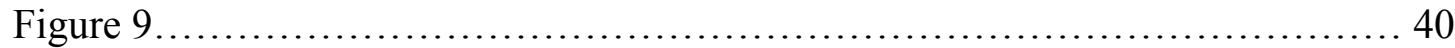




\section{INTRODUCTION}

\subsection{The Food Safety Problem}

The effects of poor food safety on a consumer are not hard to imagine. Many people have their own story of suffering from "food poisoning." Fever, diarrhea, vomiting, dehydration and cramps may come to mind but hives, headaches, broken teeth, injured esophagus, and anaphylaxis are also outcomes of poor food safety. Despite an industry full of specialists trained by research institutions, illness or injury due to consuming foods are on the rise. Using data from the years 2000-2008, one review estimates annual incidents of approximately 9.4 million events of foodborne illness, 55,961 hospitalizations, and 1,351 deaths (Scallan et al., 2011). Looking specifically at the trend of allergen-related recalls by the USDA and FDA, 2014 was the highest year evaluated since 1999 ("Food Allergy Research and Resource Program | University of NebraskaLincoln," 2015). Though the majority of people do not have a food allergy, the seriousness of an allergic reaction makes it a high risk for food safety.

Take an incident in 2015 for example. Cumin is a popular spice used in cuisine all over the world, produced in the Middle East and South Asia, among other locations. American manufacturers determined that peanut and possibly almond proteins were present in their cumin purchased from a Turkish supplier. There is speculation that peanut protein was used as an economic adulterant (i.e. adulteration of a product with a material that is cheaper and therefore decreases the cost to make the product or increases the production capacity) as a reaction to the low yielding cumin crop in 2014. The impacts are unfolding but retailers and manufacturers in the USA and UK have recalled a wide range of 
products such as spice blends and canned chili (Center for Food Safety and Applied Nutrition, 2015). The impact for consumers allergic to peanut, roughly estimated at just over $1 \%$ in the total US population (Sicherer, Muñoz-Furlong, Godbold, \& Sampson, 2010), and of $9 \%$ of US children (Branum \& Lukacs, 2009), could be dire. Symptoms include rash, difficulty breathing, and in extreme cases, anaphylaxis so severe that estimated $65 \%$ of people allergic to peanuts in the UK carry adrenaline pens to counteract the symptoms of the allergic response (Hourihane, Kilburn, Dean, \& Warner, 1997). There is no cure for food allergies; the only method for preventing an allergic response in an individual is to avoid the allergen. Consumers allergic to peanuts specifically are very cautious of eating products with any nuts due to cross-contamination concerns, because peanut allergies are the most life-threatening allergen. In the case of the cumin contamination with peanut protein, consumers are not informed of the presence of the allergen and do not know to avoid the product.

Because avoidance is the key to preventing allergic individuals from suffering potentially deadly reactions to a food, special practices must be in place to assure that foods do not contain any allergenic ingredients that are not clearly stated on the label. Unlike other food safety hazards, testing a food for allergens has been described as looking "for a needle in a haystack," due to the very small quantities of protein that can elicit an allergic response. This makes testing a food for each regulated allergen (the USA has eight foods that require labeling though each country has their own regulation) a costly, unreliable method for assuring absence of unlabeled allergens. (Cucu, Jacxsens, \& De Meulenaer, 2013). 
The food manufacturing industry, responsible for making the grocery products in every home's pantry, must prioritize food safety, including allergen management, because without it, they are liable for costly repercussions due to adverse effects on consumers. In addition to the legal liability for costs, a manufacturer may be sued in civil court by customers or charged in criminal court for negligence. The industry employs trained food scientists, chemical engineers, sensory scientists, industrial engineers, animal scientists, and microbiologists specifically to safeguard against what can be a bankrupting event: the food safety recall (Skees, Botts, \& Zeuli, 2001).

Despite the risks of recall and efforts in preventing them, food safety incidents continue to be a major public health concern. Food safety is one of the CDCs indicators of "Vital Signs", to provide a pulse on the major public health issues affecting the nation ("CDC Vital Signs,” 2014). In 2011 Congress passed the Food Safety and Modernization Act with the intent to update the Food Drug and Cosmetic Act, putting a greater focus on food safety. Since the Act passed, the FDA has not hit their milestones for actually implementing the Act. The Center for Food Safety has sued and won a court order pushing the FDA to provide guidelines and a timeline for implementation, a process that brings manufacturers' practices up to meet the Act's standards. Currently, a consent agreement has pushed back the deadline to August $30^{\text {th }}, 2015$ for the first stage of implementation ("FDA Will not Set Specific FSMA Deadlines Despite Court Order," 2014). Due to the current outdated regulatory guidelines and slow response from the FDA, the industry has had to self-regulate via third-party auditing in the name of ethical business practice, risk avoidance, and consumer confidence (P.A. Luning et al., 2009). 


\subsection{Anticipated Contribution}

The goal of this thesis is to provide a better understanding of the means by which manufactured foods can be made safely, with reduced risk of undeclared ingredients being present in a product. Currently, best practices in the industry include third-party food safety auditing, with each third-party auditing code utilizing different methods despite having the same goal: a safer food supply. More specifically, this thesis will address the growing phenomenon of the allergen-related recall by using Systems Analysis to explore the assumptions of a specific third-party food safety code, Safe Quality Food (SQF). Systems concepts have been identified as potential methods for solving food problems such as including modeling and systems analysis for food manufacturing planning (Pothukuchi, 2000) and using a conceptual model of food quality systems (P. A. Luning et al., 2009).

The research will propose three improvements on the current SQF code (Edition 7.2) as it relates to food allergens. The intent here is to show that the Safe Quality Food Institute's model of the food manufacturing system, as interpreted through their SQF Code Edition 7.2 , is missing key relationships that are often the causes of unlabeled allergens being packaged in a retail product. The result is a more robust viewpoint of interacting variables in the food safety system that should be monitored and carefully controlled in order to minimize the risk of selling a food containing an unlabeled allergen. 


\subsection{Research Question}

The question to be answered by this thesis is how can industry standards for food safety audits be improved? These audit processes are currently missing critical relationships within the food manufacturing system that could influence undeclared allergens in food. After identifying missing relationships, systems methods will be used to address the gaps and ultimately recommend ways to reduce the risk of unlabeled allergen recalls.

\subsection{Organization of the Thesis}

Section 2 provides background information regarding food safety problems stemming from the food manufacturing methods currently being used to minimize the risk of allergen recalls. Section 3 describes the methods used to answer the research question, and in Section 4 the methods are used to define the system and to identify critical relationships unaddressed by the SQF food safety code, supported with case studies illustrating these gaps. In Section 5, the results are discussed and three specific recommendations are provided to address three of the ways in which a mismanaged manufacturing system could result in an allergen-related recall. 


\section{BACKGROUND}

This section describes how food safety management is framed within the food manufacturing organization, as well as the methods historically and currently used to manage food safety. It also demonstrates the usefulness of various approaches rooted in systems theory by describing how they have been applied to managing similar systemic problems in organizations.

\subsection{Understanding Food Safety Hazards}

The definition of food safety varies depending on the institution defining it. The environment presents unique constraints on the food system and as a result, there are varied food safety standards for different countries, different food groups, and different consumer groups. For an institution focused on public health via microbial and viral outbreaks, such as the $\mathrm{CDC}$, the definition can be distilled down to the prevention of illness, disability, and death due to foodborne illness and intoxication ("CDC - Food Safety Office - Food Safety," 2014). Foodborne illness refers to the symptoms created by pathogen activity inside the body. Foodborne intoxication refers to the symptoms created by a toxin, produced by a pathogen in the food prior to eating or inside the host after eating. For an institution focused on preventable measures in the food manufacturing industry, such as the FDA, their definition of food safety can be found in the Code of Federal Regulations Title 21 sections 120 and 123 within the mandated Hazard Analysis Critical Control Point (HACCP) programs. HACCP assesses physical, chemical, and biological risks that are "reasonably likely" to cause injury or illness (in the Hazard Analysis) and uses processes that would control the hazards, should they occur (in the 
Critical Control Points) (21 C.F.R. §120.8(a)). This definition opens up food safety risks to pieces of metal, allergens, and cleaning chemicals in food, among other contaminants. As for the Critical Control Points (CCPs), scientific data is required to specify the process, but in some instances regulatory agencies offer additional optional guidance for specific risks that must be assessed for specific foods. For example, E. coli in juice processing must be controlled with a validated "kill step," which should eliminate up to $1,000,000$ bacteria per milliliter of juice, should that much bacteria be present prior to pasteurization (“Juice - Guidance for Industry,” 2004).

The importance of food safety is evident on an individual level but in the greater picture of communities, localities, and nations, food safety is valued by looking at the costs of poor food safety. Regulatory bodies provide the guidelines previously discussed and have limited enforcement abilities or resources; once an illness or injury occurs, regulatory agencies have the ability to shut down facilities and investigate the cause of the illness or injury, possibly resulting in criminal repercussions or fines. Reporting of allergen-related illness comes from a mix of consumer findings (eating a food that the consumer perceived had no allergen and having an allergic response), manufacturer self-reporting (determining that there is a risk of cross-contamination or mislabeling post-shipment of a production lot), and regulatory investigation (random sampling and evaluation from market shelves). The number of allergen reports on a given food item will greatly affect the response from regulatory authorities, as will the geography of the reports. For example, a local recall for undeclared peanut allergen may result in only a market withdrawal, whereas multi-state reports of undeclared peanut allergen will result in a 
Class I recall and fines. If there are deaths related to the product, the highest ranking organizational official, who had the ability to know about the oversight which caused the recall, may find themselves under federal criminal prosecution (Flynn, 2014).

Of the reported undeclared allergens in the FDA Recall Enterprise System (RES) collected in the first three years of the FDA's Reportable Foods Registry, causal information was provided for 231 cases. Of those cases with causal information, $35.5 \%$ were due to packaging the product with the wrong label, $25.5 \%$ were due to having the wrong language on the correct label, and $17.7 \%$ were due to failing to accurately pull information from the ingredient through to the finished product labeling statement (Gendel, Zhu, Nolan, \& Gombas, 2014). Actual allergen-related recall case studies with causal information will be used as example situations for the system gaps identified later in the Results Section.

\subsection{Quality Management in Food Manufacturing}

For the purpose of this thesis, food safety is considered a quality attribute of food products. Looking at the problem from this angle puts food safety in the arena of quality management, a topic that has been thoroughly researched in the field referred to as Total Quality Management (TQM), and within the general subject of quality control within the business management discipline. TQM traces it roots to the work of Dr. W. Edwards Deming, considered the father of statistical quality control (Aguayo, 1991). TQM also includes so-called "Lean" methodologies to reduce waste, empower employees, and deliver customer requirements. This is a linear approach of collecting data at various points in the process to reduce problems such as levels of waste produced, mistakes 
made, and customer requirements left unmet. There have been examples of TQM's success across various manufacturing industries, originating in the 1950s when Japanese automotive manufacturers began developing new methods for participatory quality management. These methods were subsequently applied to many other manufacturing and service industries (Rother, 2010). To use TQM, manufacturers often hire consultants or "lean practitioners" to train their employees in lean concepts and to help them develop quality policies that demonstrate an company's conformance to given standards (van der Spiegel, Luning, Ziggers, \& Jongen, 2003). This involvement of third parties in policy development has led to the current use of standardized guidelines for policy development, with the option to be certified by the publisher of the guideline. It is the goal of the Global Food Safety Initiative (GFSI) to designate which standardized guidelines meet the highest standards in food safety. Potential customers of a food manufacturer, such as retailers or food service companies, can use the presence of a GFSI approved food safety certification to determine confidence in the manufacturer's food safety policies without having to physically see the manufacturing process or the food safety policy manual.

Outside of the audit framework, the human factor has been considered an important aspect of maintaining quality in TQM and in Lean manufacturing, because operational processes rely on individuals making good decisions. More recently, survey results have shown that management outlook, goals, and organizational culture greatly impacts the effectiveness of food safety programs in food manufacturing (Milios, et al.,2013). This type of research uses the terminology of "techno-managerial" factors in executing food safety. This is a conceptual descriptor signaling a higher level look at the interactions 
happening in a food manufacturing organization, much like the conceptual model proposed by Luning and Marcelis (2007), which acknowledges the environment, the human component of manufacturing, the technical component of management, and the physical (material) component of manufacturing foods. Though their work looks similar to some of the methods used in Operational Research and various Systems Science theories, they do not reference Systems Science concepts or applications. At the time of this thesis, a thorough literature search in Web of Science, Google Scholar, and PubMed of the topics "food safety," and "Systems Approach," or "Operational Research," yields few results, none of which actually use these methods for research.

Published research into food safety management is still referencing Deming's work in statistical process control, though those methods of quality control do not address the human component - an element in the organization which has proven effect on food safety outcomes. The next section describes some methods related to Systems Science that show good potential to be applied to the food safety problem.

\subsection{Utilizing Systems Methodologies}

Systems Methodologies are methods stemming from Systems Science concepts to better define a system or problem, identify a better system structure to improve the system state, or identify the relationships within a system that could potentially create the most impact for the least amount of effort or change, among other outcomes. There are several different approaches or methodologies used by practitioners but the approaches share a common systems language of boundaries, sub-systems, elements, relations between elements, information feedback, constraints, and intervention points. 


\subsubsection{Example of Total Systems Intervention}

Flood and Jackson developed a methodology based on their theory of Critical Systems Thinking called Total Systems Intervention (TSI) (1991). TSI is their critical response to the systems methodologies that were already in practice and in their opinion, sometimes applied by practitioners in haphazard ways. Their argument is that each systems method is rooted in a theoretical rationality which applies only to certain types of systems. TSI provides a framework for deciding which methods can be complimentarily applied to a system based on specific systems characteristics. TSI also incorporates the idea that certain methodologies became popular due to the environments in which they were developed, so a type of social awareness is relevant to choosing a method as well. If a system is oriented toward achieving an objective, singular goal, then hard systems methodologies that work to solve specific problems apply. If a system has multiple stakeholders who do not agree on the goal of the system, then they likely do not agree on what the ideal system state would be, so soft systems methodologies that work to identify problems and define systems apply.

By using the system and environmental characteristics as criteria, TSI can assist the practitioner in making a theory-based choice of mixed methods for improving the performance of a given system. Additionally, TSI seeks to assure that all individuals touched by the systems in question reach their maximum potential. This method applies very clearly to systems similar to the food manufacturing system. Different stakeholders have different views of the ultimate goal (e.g. quality vs quantity), the organization may be more objective and resolution focused than subjective and improvement focused, and 
each food manufacturing organization must rely on the people involved to be as effective and fulfilled in their roles as possible (Flood \& Jackson, 1991).

\subsubsection{Example of Mixing Two Systems Approaches}

Critical Systems Thinking is not the only theory that makes use of combined systems approaches to make up for the shortcomings of the individual approaches. In the arena of Operational Research, practitioners have been combining methods to solve operational problems for private and public organizations. One example is the mixing of the robust, holistic picture of the system offered in Soft Systems Methodology with the more quantitative problem solving approach of Systems Dynamics which will be explained in this section (Lane \& Oliva, 1998). This mixed method is well-suited for operations practitioners who have a specific problem to solve but whose general understanding of the overall system lacks rich detail. In such a situation, these two methodologies can help to compensate for each other's shortcomings.

Systems Dynamics

The Systems Dynamics method strives to create a simple problem-specific model of the system. Only elements and relations that affect the desired (or undesired) outcome are included in the model. The concepts of flow, rates of flow, accumulations, and feedback are used to show that the behavior of a system is a product of the structure of the system. A generic example is how the changes in population levels of a predator/prey system are cyclic as a result of their interdependencies. These models do not evaluate the numerous variables that could affect a population of organisms, rather they focus only on the 
predator/prey relationship because the purpose of that model is to better understand that cyclic behavior.

\section{Soft Systems Methodology}

Soft Systems Methodology (SSM), named for its focus on cultural and societal influences on a system, is a contrast to what is considered "Hard" Systems Methodologies that use more quantitative means to describe systems or solve problems. SSM purposefully does not identify a problem to solve but offers continuous improvement of the system to a more desirable state by creating a rich model of the system, which can be shared by different stakeholders in the organization (Petkov, Petkova, Andrew, \& Nepal, 2007). The perspectives of individuals involved in the system are evaluated to better define the problem situation in the system before a rich model of the system is created, using those perspectives as they relate to a task or as they relate to a point of interest in the system. This model is then related back to the problem to ensure that it accurately depicts the task or all influencing relationships on the topic. Changes to improve the system state are developed and checked against the reality of the culture of individuals in the system for feasibility, but no prescription for implementing change is made in this method. The goal is to better define the problem and to get invested individuals to agree on a theoretical ideal system state.

The two methodologies in this example are complementary due to the problem solving abilities of System Dynamics and the scrutinizing/system-defining abilities of Soft Systems Methodology. When used in combination, they may be useful for a specific type 
of system problem that involves a social component as well as a measureable task or point of interest.

\subsection{A Gap in the Literature: Applying Systems Methodologies to Food Safety}

Well established research in the food sciences and business touch on topics relevant to food safety management. Such research primarily uses methodologies from chemical, microbiological, or physical sciences as well as statistical quality control. Relevant research utilizing a systems approach has been relatively limited. The following are examples of systems methodologies that have been used to address problems related to food safety management. The models do not delve into the manufacturing process or quality control, but they do show successful efforts to use systems methods to describe and better understand key aspects of our food system.

\subsubsection{Systems Methodologies in Food Safety Adjacent Systems}

Simulations of pathogen growth through the supply chain (Halder et al., 2011) and epidemiological models of zoonosis pathogens in stock animals (Chebolu-Subramanian \& Gaukler, 2015) have been used to illustrate how changing conditions of the food matrix, packaging, and storage can affect microbial food safety loads. Milios, et al. (2013) consider the interaction between the human and physical-technical systems in food manufacturing and the impact on food safety performance. Those examples aside, systems methodologies, or disciplines like operations research that take a systems perspective, have rarely been used to address food safety in general, or the specific factors needed to assure food safety. 


\subsubsection{Conceptual Models of the Food Manufacturing System}

\section{The Producer, Consumer, Nutrition System}

One high-level model of the food system (Sobal, Kettel Khan, \& Bisogni, 1998)

identifies three sub-systems of Producer, Consumer, and Nutrition (see Figure 1). This model places food safety within the Nutrition sub-system as a way to describe one aspect of how the customer interacts with food. The Sobal model further divides the Producer subsystem into three sub-sub-systems of Production, Processing, and Distribution without any discussion of the interactions within that Producer sub-system. This compelling conceptual model provides a description of the "food and nutrition" system at a high level but does little to explore the subsystems in enough detail to allow for meaningful systems analysis or optimization. Firstly, the Sobal model portrays only the general input, output, and relationship between the three sub-systems, resources, and environment. 
Figure 1. The Food and Nutrition System (Sobal, et al, 1998) Simplified

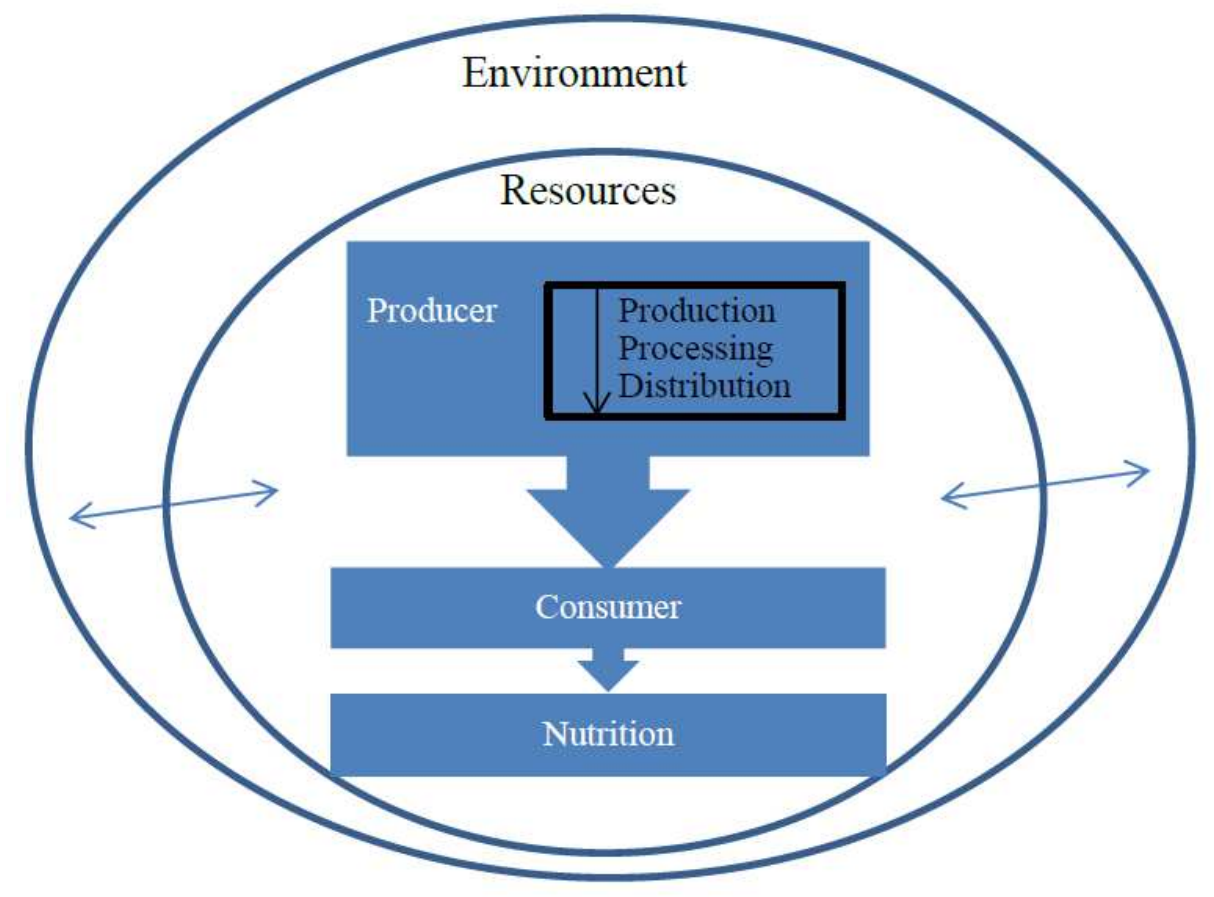

Secondly, it is not useful to look at the system as a chain when there are a series of feedback loops that influence decision-making at each step in the process. An updated version of the high level model is suggested in Figure 2, which shows the feedback connections that provide constraints on the Producer subsystem from external subsystems Consumer and Nutrition.

Due to the lack of detail in Sobal's Producer subsystem, this conceptual framework is not sufficient for the analysis proposed by this thesis. To better understand the constraint of food safety in the food manufacturing system, as discussed previously, relations between sub-system elements must be scrutinized for richer detail. 
Figure 2. Updated Food and Nutrition System with Feedback Loops



\section{Understanding Food Quality as It Relates to Supply Chain Reliability}

A more granular framework for understanding the food system is presented by Manzini and Accorsi (2013) for food supply chain assessments. They found numerous models that depict the logistics of distribution in the food supply chain but very little for the attributes of the food or the production of the food. They highlight a need for predictive modeling of the deterioration of food for spoilage, but they treat food safety as part of the environment with respect to their model. This includes quality, safety, sustainability, and efficiency within which the food supply chain functions. These functions are separated into "Original-Final Steps" (e.g. resources are harvested, wastes are composted), "Manufacturing and Processing," and "Forward-Reverse Logistics". Their inclusion of quality and safety as requirements for the food supply chain are due to the increased cost of "Reverse Logistics," or shipping non-conforming materials back one step in the supply chain. These predictive models have useful applications in predicting changes within the food material matrix over time, which serves as good validation information for making policy decisions specific to shelf life, transport, and storage conditions. The model does 
not provide insight into how management can improve the ability of the food manufacturing system to produce assured safe food, though it does provide an example of useful application of systems concepts to the food system.

\subsection{Background Summary}

This section provided context for the research goal of using systems methods to find gaps in current food safety guidelines and possibly offer recommendations for improving the food manufacturing system's ability to assure safe food production. Current food safety guidelines are based upon years of successful research including statistical quality control and Total Quality Management but the increasing incidences of allergen recalls in the US points to ineffective guidelines.

Systems methods are being used complimentarily either by way of researcher decision or by following a framework such as Total Systems Intervention. When combining systems methods, understanding the theoretical basis on which the method was created is necessary to ensure effective use because each system has a set of characteristics or is part of an environment that translates well or poorly to certain methods.

Some researchers have applied systems thinking to the food manufacturing system or to aspects of the food safety system, in an effort to describe the unique problems facing these systems; others have noted the possible usefulness of applying systems methods to improve food safety management, a gap which this thesis will attempt to fill. 


\section{METHODS}

This research uses systems methodologies that are complementary in theoretical basis to improve those parts of the Food Manufacturing System related to allergen control. The basis for choosing the methodologies is the TSI framework, which would evaluate the food manufacturing system as a Simple-Unitary system. This means that the food manufacturing system is a simple goal-oriented system (financial success) and the goal is shared by all stakeholders in the system (all employees of the organization benefit from the same goal of financial success). In the Simple-Unitary systems type, recommended systems methodologies include general systems theory and systems analysis. (Flood \& Jackson, 1991)

The first phase of this method is to use general systems theory to create a rich, detailed model of the socio-technical Food Manufacturing System, using the SQF Code as the reference point. The code is organized in a way that highlights the parts of the business that require food safety policies and the relationships between those parts. This information is translated into a systems model using the concepts of elements, relations, flow, feedback, and boundaries to better understand SQFI's ideal food manufacturing system. This phase includes discussing the Food Manufacturing System's complexity within and between sub-systems to better understand the interactions between the social/cultural context of the organization and the physical/biological context of the manufacturing activities.

The second phase of research is to use systems analysis to make recommendations for managing allergen-related risks, detailed in Table 1. The developed food manufacturing 
system model is evaluated against US allergen recall data to identify gaps in the SQF code, which are then addressed using mixed systems methodologies to improve those sections of the SQF code. These recommendations apply several methodologies.

Feedback theory is used to evaluate parallel processes in the organization that create delays in finished product shipments or delays in food safety evaluation of the finished products. Purposeful action helps describe the theory behind HACCP, highlighting an important step in a successful HACCP plan that is not adequately specified in the SQF Code. Finally, the socio-cultural aspect of a food manufacturing system is viewed as a hierarchical system, allowing a clearer picture of the organization's responsibility to manage competing business goals as a source of conflict between individuals in different roles.

Table 1. Systems solutions paired with causes of allergen-related recalls

\begin{tabular}{|c|c|}
\hline Proposed SQF code improvement & Cause for allergen-related recall \\
\hline \#1. Feedback delay reduction & $\begin{array}{c}25.5 \% \text { Allergen Recalls } \\
\text { Using an approved label with an error in } \\
\text { the ingredient statement }\end{array}$ \\
\hline $\begin{array}{c}\text { \#2. Harness purposeful } \\
\text { action theory for more } \\
\text { effective HACCP }\end{array}$ & $\begin{array}{c}17.7 \% \text { Allergen Recalls } \\
\text { \#3. Evaluate all levels of the } \\
\text { organizational hierarchy for food safety } \\
\text { culture }\end{array}$ \\
$\begin{array}{c}\text { Unverified label after ingredients } \\
\text { or formulas changed }\end{array}$ \\
\hline
\end{tabular}




\section{RESULTS}

\subsection{Creating a Rich Model}

Quality and food safety standards created by private, third-party groups are voluntarily adopted for various reasons. The industry is aware that food safety is the most important attribute to prospective consumers and that the negative effects of poor food safety can have industry-wide implications (Fulponi, 2006). The limitations of an audit-based approach to meeting standards have been discussed in public and academic settings because facilities with good audit scores are still experiencing recalls. For example, one multi-state outbreak of Salmonella in 2010 was from a peanut butter processing facility in New Mexico that received over $90 \%$ scores on all historical food safety audits. After thorough investigation, Salmonella was found in the walls of the processing facility and identified as the contamination source (Weise, 2012). One problem in this audit scenario is that an auditor hired to assess a food safety of a facility is not likely to fail a manufacturing operation. The auditor only sees a snapshot in time of how the facility operates, is not invested in the safety of the foods being produced, and receives benefit from passing the facility. Ultimately, the auditor makes their money from issuing certifications - they charge for the audit as well but they may lose their client (the manufacturer being audited) if the audit does not result in a certification. There are always other certifying bodies that can send an auditor and issue the same food safety certification (D.A. Powell et al., 2013).

Several food safety codes are well regarded in the industry because they meet the Global Food Safety Initiative (GFSI) benchmark for a food safety certification, which launched 
in May 2000 in Belgium. The GFSI was created as an umbrella standard to standardize food safety management programs across different companies in different countries, as a response to a globalized food market. The plan was to create a group of different food safety certifications that would be considered equally stringent, which would benefit organizations that had multiple costly food safety certifications to appease multiple customers (Valder, 2009). Due to the nature of third-party certification requirements by retail and contract manufacturing clients, it is not uncommon for one organization to have multiple customers requiring different third-party food safety certifications. In theory, requiring GFSI compliance would eliminate this redundancy for the manufacturer, allowing the manufacturer to pick just one GFSI benchmarked certification and maintain compliance with customer needs.

SQF is one of the food safety schemes recognized by GFSI. It is widely used in the US food industry and, due to its integration at all points in the food system, it is a good model of the food safety system to look at as a case study. The method of assuring safe food via the SQF code (e.g. monitoring and record keeping) is not the focus of this analysis. Rather, the connections in the SQF code (assuming Level 2 certification and using modules 2 and 11, which apply to most food manufacturing categories) were evaluated to create the food safety system model that details the materials and information being used and created in the manufacturing operation.

\subsubsection{The Viewpoint in the SQF Code}

The Safe Quality Food Institute is a division of the Food Marketing Institute established in 2003 (Valder, 2009). They have most recently released Edition 7.1 of their SQF Code, 
which is a HACCP-based food safety and quality program that can be used in any food category (Food Marketing Institute, 2013). It is applicable to organizations across the food chain, from farm-level agricultural producers through food retailers, with customized code modules relevant to 35 defined different business categories. Organizations can adopt one of three levels in the SQF standard, against which a certifying body will audit, score, and certify the organization. Level 1 requires basic record-keeping and adherence to the Good Agricultural/Manufacturing/Distribution Practices for the specific industry sector category. Level 2 requires implementation of a HACCP food safety plan, including prerequisite programs deemed necessary as the groundwork for a successful HACCP plan. Level 3 requires implementation of a HACCP-based food quality plan, separate from food safety which addresses hazards to meeting the quality specifications for a product (SQF 7.2, Part B, Module 1(a)). The audit is carried out in two parts: the first audit is to ensure that the written policies and procedures meet the requirements of the code and the second audit is no less than three months later, at the facility, to view records and these policies in practice.

The code identifies activities in the food manufacturing system that relate to food safety controls and ultimately the creation of foods with low food safety risk. Using Figure 3, the reader can see the relationships of the following sub-systems and process steps.

\section{Environment}

Facilities must meet local, state, and federal regulatory guidelines for security, maintenance, clean-ability, and location. In areas where materials are open to contact, 
Figure 3. Food Manufacturing Model per SQF Edition 7.2, showing influence (dotted arrows) and material flows (solid arrows) as well as sub-systems boundaries (solid lines)

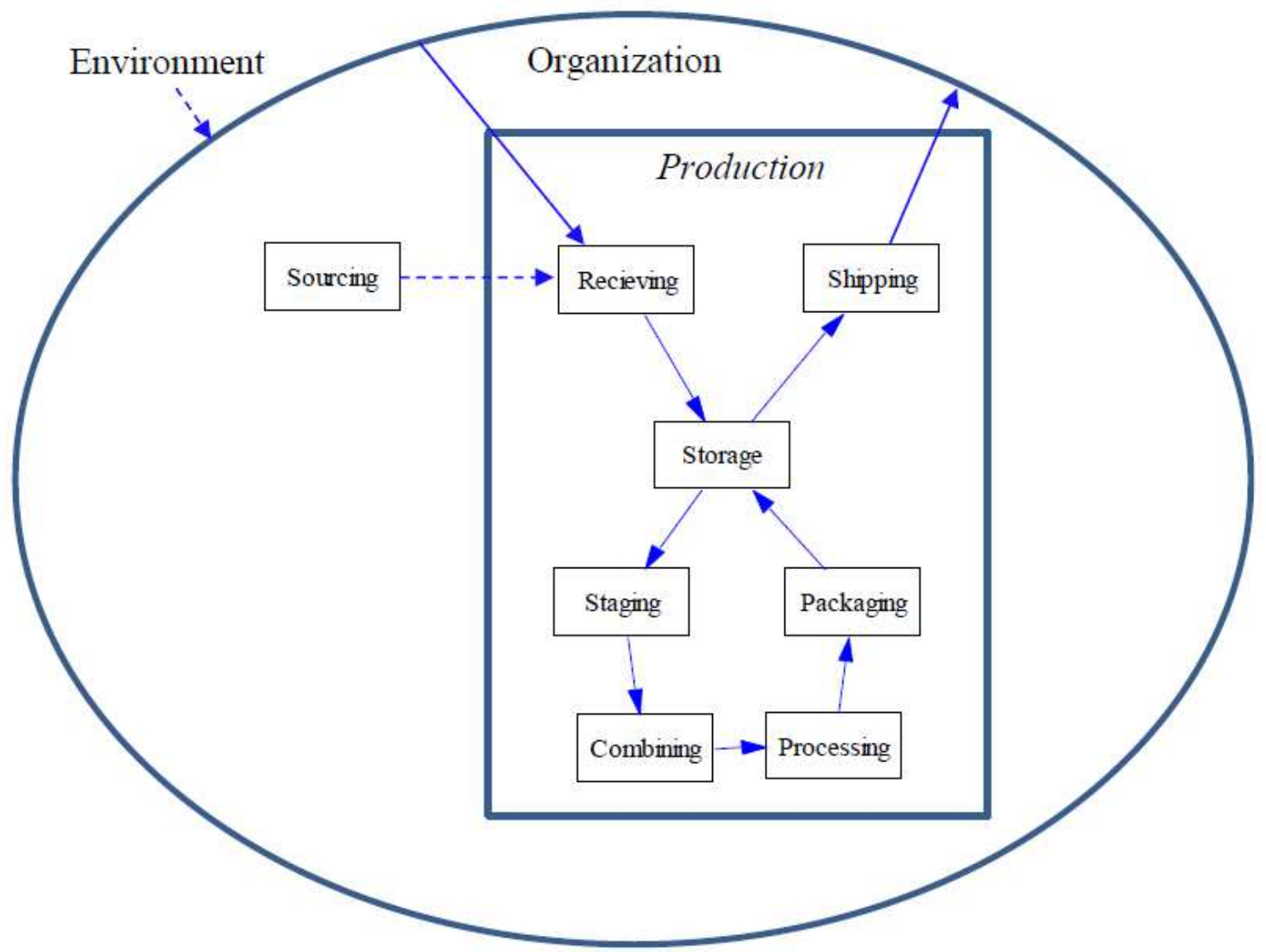

there must be adequate cleaning activities and verification that the environment was clean prior to production activities. The environment of the facility must not create a food safety contamination risk.

\section{Organization (Sub-System)}

The business producing food must be licensed with state and federal regulating agencies.

Employees must receive training on company food safety policy. Management must support the food safety initiative and there must be a manager responsible for giving employees the resources necessary to make safe food. Identifying these resources is up to 
management. Employees with responsibility for food safety must be aware and accountable for facility activities following food safety policy.

\section{Production (Sub-System)}

The department within the organization that carries out the production process is responsible for specific steps that relate to food safety. The employees of this department must have more detailed food safety training that relates to the tasks of handling and transforming food from one process to the next.

\section{Sourcing (Information Flow)}

For a food manufacturing process, the SQF code (assuming Level 2 for the purposes of this analysis) begins with a responsibility to validate safe vendors and verify upon receipt that vendors send exactly what was purchased. Vendors must show proof via certification that they employ some level of quality and food safety practices in their own operation and maintain liability if their materials do not fit regulatory standards.

\section{Receiving (Information and Material Flows)}

Employees must be able to identify potential product tampering and contamination, intentional and unintentional, while receiving ingredients and packaging. Documentation provided by the vendor will be verified against the documentation accompanying the shipment, including exterior labels. These labels must not only indicate the item and a unique lot code for traceability purposes, but must also clearly list ingredients. 


\section{Storage (Material Flow)}

All materials, ingredients, finished product, and packaging that will be touching the food (i.e. primary packaging) must be sealed and allergenic ingredients must be separated from non-allergenic materials. If materials are temperature sensitive, cold storage locations must have accurate temperature recording devices, showing temperatures in the allowed range (be it refrigeration or freezing). Any materials that do not conform to quality or food safety requirements must be identified as nonconforming and segregated from acceptable materials until a disposition is determined.

Staging for Use (Information and Material Flow)

The materials staged or pulled from storage for use must be intended for the product being produced, labeled effectively for traceability, and physically staged in a location not detrimental to the food safety of the staged materials.

\section{Combining (Information and Material Flow)}

The quantity and traceable lot code of the materials combined must be recorded. Once these materials are combined, they must be labeled with their contents and a traceable lot code for identification purposes. The traceable lot code must be unique for at least every 24 hours of production. Any tool or surface that comes into contact with the food must be designed for their use and made of food safe materials.

\section{Processing (Information and Material Flow)}

Equipment used in each processing step, regardless of how manual or automatic, must be inspected as clean and in good condition. Any steps deemed critical to the food safety of 
the material being produced must be monitored and recorded by trained employees. Allowable limits are predetermined and should this monitoring show results outside the allowable range, a predetermined corrective action plan must be followed and recorded.

\section{Packaging (Information and Material Flow)}

A finished good must meet quality standards set for the product. The packaging used for the product must meet regulatory guidelines and be the correct packaging item for the specific product built. The packaging must also display the traceable lot code used on all records maintained for this product. This information must be available for auditing purposes in the future.

\section{Storing before Sale (Information and Material Flow)}

Only materials that have cleared all food safety and quality criteria with complete records may be released to leave the facility. If products have not been expressly released, they may not be staged for sale.

\section{Shipping (Information and Material Flow)}

Any transport vehicles must have written documentation linking this shipment to the specific products contained and the customer. Security of the vehicle and the identity of the driver must be verified prior to release of product.

\section{SQF System Model Summary}

The Safe Quality Food Institute has determined that food manufacturing organizations must take precautions regarding the food system they are operating within and the 
manufacturing system they control. Each of the steps highlighted in the model have procedures outlining what should be happening when the process is in control, as well as the corrective action to take if the process is not in control. Employees must show proof of understanding their training, must have access to adequate bathroom and break room facilities, and must have demonstrated awareness of their part in the food safety plan.

The model representing food manufacturing system from the perspective of the SQF code presents a HACCP-based approach for a food manufacturing organization to reduce the general food safety risks and those hazards specific to the nature of the foods being produced. For those risks that cannot be reduced by policies and procedures, critical control processes are validated to control the hazard (should it enter the system), verified to have been functioning during specific production runs, and monitored in case they should fail. This model contains the elements, relationships, and sub-systems that influence the production of safe food, based on specific, scientifically and anecdotally supported relationships between food, processes, and environments found in food manufacturing.

\subsubsection{Identifying Complexity in Food Manufacturing and Food Safety}

The amount of elements, relationships, and the number of different states the elements present can be used to quantify the complexity of a system (Schneider \& Somers, 2006). It is the responsibility of an organization's managers to keep the system in an advantageous state; organizational management has been described by Taiwo as the act of decision making, policy making, and continuous improvement, (Taiwo, 2001; Glenn \& Malott, 2006). The food manufacturing system is a physical system of elements and 
relations being run by a team of people. The elements and relations in the production subsystem are complex and the relationship between the sub-system and decision makers in the organization adds an additional level of complexity to food manufacturing systems. This idea is illustrated in Figure 4, showing the sub-systems of the food material, the manufacturing process, and the management activities. Each larger sub-system interacts with the lower sub-system, e.g. the manufacturing process changes the dynamics of the food material by cooking it, altering its physical structure and microbiological contents.

Figure 4. Complexity in sub-systems of the food manufacturing system

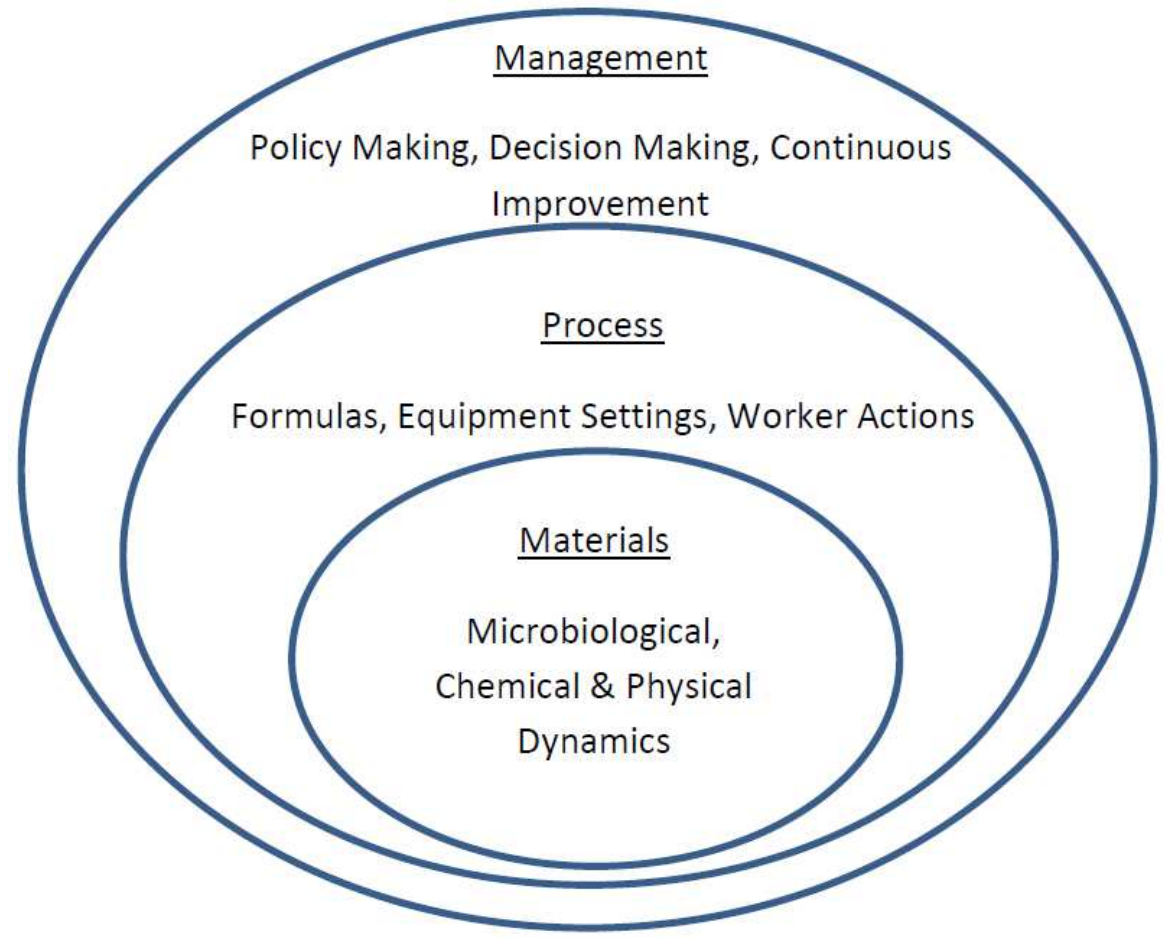

One way that food manufacturing has increased complexity over other forms of manufacturing is through the materials being handled. Food is a biological material with microbial flora, chemical attributes, and a physical structure, all of which can change over time. Consider the use of butter as an example material. If the organization's 
valuation of this butter decreases over time, the material may no longer be useful for the company. Adding more complexity, before the pallet of butter arrives at the facility, it has been evaluated as safe and of a quality required by the company. This effort to evaluate the product is an example of adding value to a material - just in being chosen by the organization, this material has much more value than the inherent value of the butter. The information received and the decision made regarding the butter is the relationship of this specific butter to this specific organization, which adds complexity. Should one of the pieces of information about the butter change (e.g. the butter manufacturer's food safety certification expired), this specific butter may no longer be valuable. This is a problem unique to manufacturing products from biological materials.

Relevant to this thesis, even more complexity lies in the butter example. The butter contains milk protein, an allergen. The chemical nature of an allergen protein can be used for quantification purposes but there are several methods available; these different analytical methods provide different results even on the same sample of food. The ability to analytically quantify an allergen in a material is a complex relationship involving minimum detection levels, alternative methods, and uncertain risk assessments (Cucu et al., 2013). The levels of complexity through and between the various sub-systems present unique management challenges in food manufacturing.

Managers in food manufacturing can crumble under the complexity of this environment or excel at operating within such an environment, depending on the organization's flexibility within its operating procedures. If an organization is too rigid and inflexible, it could be unable to produce should an inconsequential detail change about one ingredient 
material. If an organization is too lenient and flexible, it could continue production even though a detail impacting food safety has changed in one ingredient material. Theories about the "edge of chaos" in complex adaptive systems have been applied to organizations to explore the phenomenon of robust organizations that adjust in response to unpredictable changes but also maintain limits to those adjustments (Schneider \& Somers, 2006). The "edge of chaos" is a place where increasing complexity in a system fosters innovation and continuous improvement, without allowing so much complexity that the system becomes unpredictable, or uncontrollable in the case of a managed system, and therefore chaotic (Kauffman, 1995). A company without the flexibility to address the complexity in its environment may strive to operate the same way all the time (not changing with the environment), and end up missing out on new trends or economically beneficial vendor partnerships. In the earlier butter example, a robust organization would have already evaluated options and be able to quickly switch to a new supplier of butter with a favorable price difference. An organization that looks for the cheapest butter supplier each time they order, without evaluating the potential impact on food safety might be pushed into a chaotic state if a supplier issue surfaces. Systems that allow too much complexity can devolve into chaos but there is a degree of complexity that a robust business can successfully accommodate.

\subsection{Systems Analysis of the Allergen-Related Recall}

The model created to represent the food manufacturing system from the SQF viewpoint, along with understanding the unique complexities of food manufacturing, provides an opportunity to identify several relationships important to food safety that are missing 
from the SQF code. The following are three recommendations for improving management of allergen risks. Each recommendation is supported with a case study of an allergen recall from 2015 in the USA.

\subsubsection{Proactive Use of Feedback in Critical Control Points.}

Before the major outbreaks of the 1980 s, the generally accepted form of quality control in food manufacturing was inspection, a reactionary, error-controlled method of regulating product defects. A sample of produced food is tested for a defect, a defect rate in the production lot is determined, and the rate is compared against standards for allowable defect rates specified by regulatory or customer requirements. Because it allows the error to happen before a change is made in the system, the result of this method is large production lots sitting in quarantine to be reprocessed, repurposed as animal feed, or destroyed (Grant \& Leavenworth, 1980). The quality assurance movement that followed focused on preventative action by sampling further upstream in the process, to prevent a defect from becoming a finished good. This was still error-controlled regulation, though it was modified to prevent large defect rates in a finished product volume, thus limiting the amount of rejected finished goods. This was important in manufacturing because the sooner an intervention takes place in the process, the less value the company is adding to the defective material and the less money is lost should the material be disposed.

When HACCP came about, it was the first time modified cause-controlled regulation was successfully and broadly applied to food safety defects. To mediate the risk of defective material, prerequisite programs, such as vendor approval and sanitation, have become an important foundational component of HACCP. Prerequisite programs are intended to 
reduce risks at their sources, at the ingredient supplier or during the equipment sanitation activities, instead of waiting for a defect to signal a problem. The prerequisite programs are sufficiently emphasized in SQF for good reason, especially when it comes to allergen control. The prerequisite program is especially useful in preventing allergens due to the barely detectable levels that can be present and cause an allergic reaction. Due to the low likelihood that residual allergen protein is discovered via testing (which is a form of inspection), allergen control relies heavily on monitoring ingredients and production activities; in HACCP, allergen control is considered a prerequisite program, although, for a high risk product, an additional label verification step during processing can provide a critical control point.

The SQF code relies heavily on validated effective procedures, monitored critical control points (CCPs), and verified daily practices to preemptively guard the consumer against contamination. In practice, the activity of monitoring a CCP is done by a trained individual on some regular frequency. If the attributes being monitored (e.g. volumetric speed through a sterilizer and sterilizer temperature) are outside of the validated allowable limits, a corrective action is carried out; the material that had an insufficient CCP step, a failure, must be separated as non-conforming material and may need to be reprocessed or destroyed.

\section{The Missing Step}

Though this method has reduced the amount of defective food produced by a facility, it still only goes into effect once suspect food has been produced. That defective food must either be disposed or reprocessed, resulting in economic loss for the facility. The review 
of HACCP records is so delayed, only occurring after a production day is complete, that organizations may presumptively ship products prior to completing all HACCP record verification, allowing the possibility of recalls and consumer illness or injury. This is so prevalent that the FDA has required that manufacturing facilities self-report when they allow potentially hazardous foods out of their control, even if it is only in transit (Gendel, 2013). Looking at the FDA's reportable foods reports, the last two years of available data from September 2011 to September 2013, show that undeclared allergen was the number one reason for a company to self-report (US Food and Drug Administration, 2014). This evidence would indicate that the HACCP-based food safety plan, though an improvement over inspection, is not effectively controlling allergen related risks from entering the food supply.

The processes depicted in Figure 5 show the simplified flow of materials through the CCP process to make a controlled, safe product on top and a simplified information flow on the bottom. These two processes are occurring in parallel and intersect when the production process is monitored hourly $(\mathrm{t}=1 \mathrm{hr})$ throughout the production run. A third party, usually a supervisor or manager responsible for HACCP, must review the record and verify that the foods produced met all HACCP critical limits at each CCP monitoring check. An organization can determine, based on their own risk assessment, how quickly that documentation must be reviewed after the production date is finished. Meanwhile, at the end of the production day $(\mathrm{t}=24 \mathrm{hr})$, the finished product is put into storage and is physically able to be shipped. The feedback from the information process is not fast 
enough to be real time with the production process; the result can mean release of products for shipment without full food safety verification.

Recommendation: Include Verification Activities in the Manufacturing Process If $\mathrm{SQF}$ is going to rely on verification of monitoring records to control for CCP deviations and failures, the verification process needs to be embedded into the production process, as depicted in Figure 6. 
Figure 5. Food production process with material flow (top) and parallel HACCP verification process with information flow (bottom).

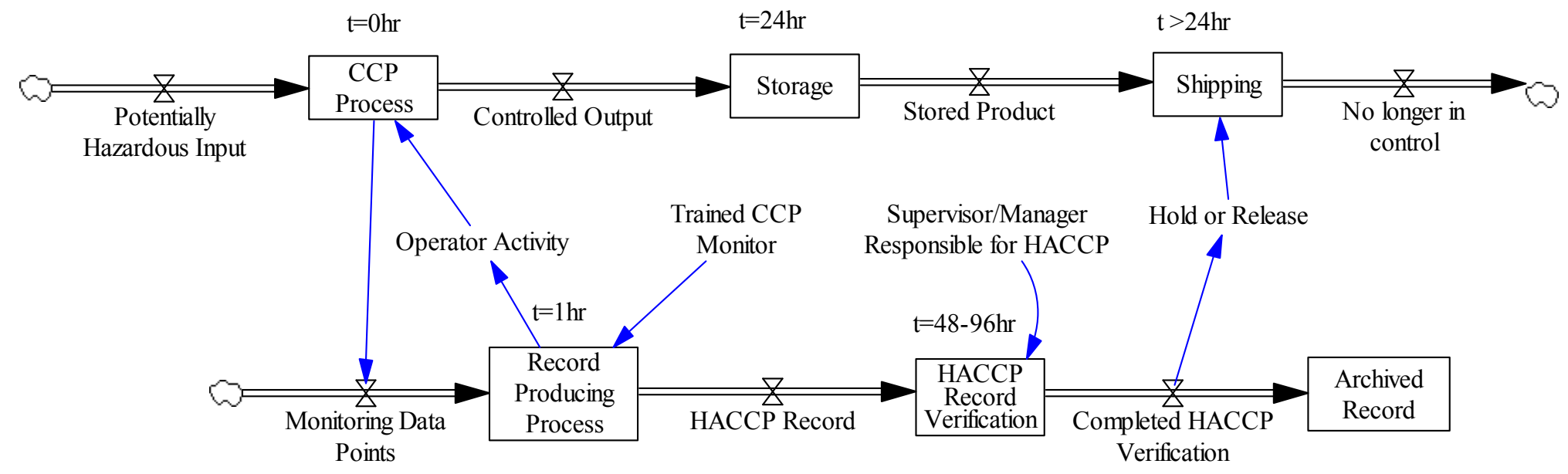

Figure 6. Integration of recommendations such that HACCP verification has influence on the food production process, allowing the release of product.



๙ 
Monitoring could be integrated, carried out by the same operator who runs the CCP equipment and verification can be done intermittently by a supervisor. Focusing on shortening the feedback delay from the documentation review is a simple way to make the SQF code more robust, considering that true cause-controlled regulation of CCPs is not realistic in a system with so many sources of hazards. The main difference between the current model in Figure 5 and the recommended model in Figure 6 is that the HACCP verification activities are no longer their own process; they are integrated as influencing factors into the food production process as a requirement before a material in storage is moved to shipping.

\subsubsection{Case Study: Verification Activities in Parallel with Production}

In a press release from Tarrier Foods Co. on January 16, 2015, the Columbus, Ohio company notified the public that a confectionary product contained peanuts and egg as an ingredient, although it was not declared on the product ingredient statement. The error was discovered after distribution (US Food and Drug Administration, 2015b). According to the SQFI database, this organization is SQF Level 2 certified (SQFI Reliance, 2015).

The report did not clearly state how it was determined that there was a problem after distribution. The company's product review procedures should be re-evaluated for activities that could prevent a mistake. These activities must take place prior to the process of placing the label on the packaged foods. This would prevent the incorrect labels from being used on a sellable product, which can misinform the consumer about the allergen content of the food. The material should not have physically left the production facility prior to verifying the packaging and formula information. 


\subsubsection{HACCP as a Tetrad}

The SQF code is HACCP-based, meaning that the principles of the HACCP program are central to the ideology and practice of the SQF code. HACCP started in 1959 when Pillsbury was contacted to provide food for astronauts in NASA (Bauman, 1995). The program as it exists now has been adopted by the FDA in their Food Safety and Modernization Act of 2011. Before that, it was required for specific industries with high food safety risks (e.g. the juice industry's history with the E. coli O157:H7 strain). There are seven steps to creating a HACCP plan for a given process, but once the plan becomes active, there are four continually occurring activities in a successful HACCP plan. These activities follow a tetrad, similar to the action system theoretical framework presented by Talcott Parsons (1966; 1971), shown in Figure 7.

Figure 7. Purposeful Action (Bennett, 1966) is a plan for continual improvement

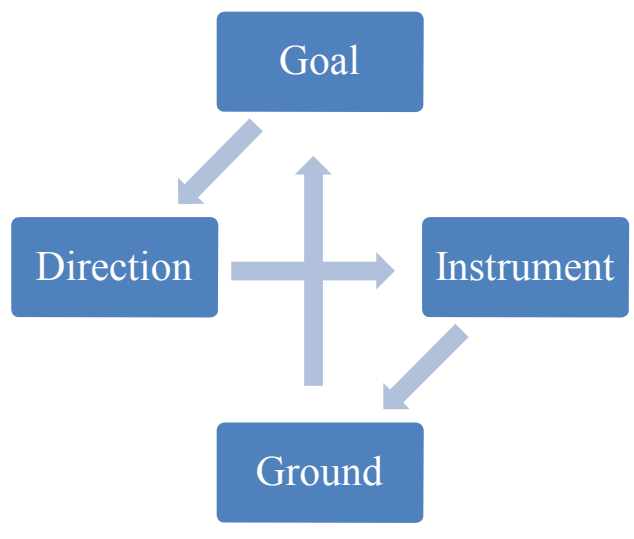

This illustrates the relationship of a goal creating an idea for action or direction, which is then carried out (instrument), to affect the actual situation (ground), which can be compared to the goal again to iteratively continue moving closer toward the goal. This is 
very similar to a gap analysis, the center tetrad, where a standard is the goal, theory gives us an idea of how to attain the standard, action is taken based on the theory, and the resulting reality can then be compared again to the standard. This is a cycle of continual action, and the GAP analysis in Figure 8 starts the cycle by defining reality, to determine the difference between reality and the standard, which is used in the food industry when an organization adopts a new certification standard.

Figure 8. The steps of a GAP Analysis in the format of the Purposeful Action tetrad

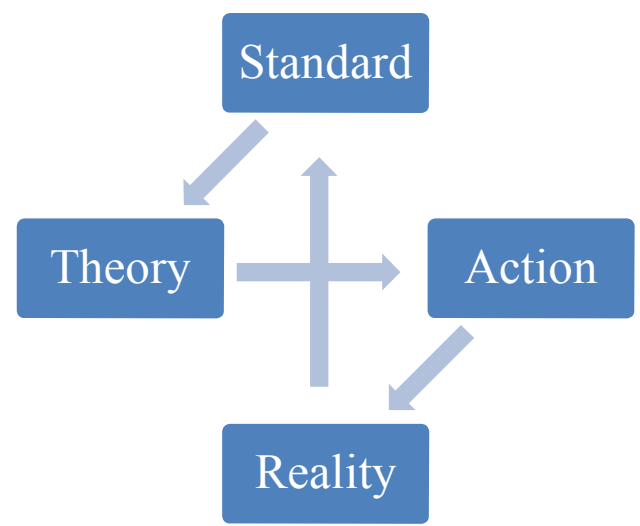

The Missing Step: Comparing Reality to the Standard

HACCP can be considered a method to solve the problem of poor food safety, which follows a similar tetradic pattern. In Figure 9, the general goal is food safety and scientific literature or experimental data provide validation for the method of obtaining food safety, which determines the control step put in use by the organization. The control step is monitored, creating records which are verified to have met predetermined critical limits. The results of verification are used to assess the reality of the production activities, which are then compared to the food safety standard. This relationship, highlighted in Figure 7 
with the darker arrow, is used to determine if the HACCP plan has actually been effective. The link between verification and food safety is the step that is not explicit in HACCP or in the SQF code; annual review of the effectiveness of the HACCP plan is required but the method of doing so is not prescribed.

Figure 9. Key points of a Hazard Analysis Critical Control Point plan, following the Purposeful Action tetrad similarly to the GAP Analysis



Recommendation: Prescribed Frequency of HACCP Plan Review

Based on the theory of problem solving provided by Bennett, adding a gap assessment between reality and the food safety goal is an area that SQFI should develop. This is supported by various models in early quality control, such as a generalized model presented by Deming, relating quality control to a rotating wheel: planning, doing, checking results, and action (Grant \& Leavenworth, 1980). It is the continuation of planning - continuous improvement - after an initial action that keeps Deming's wheel rolling. This component of HACCP is not new but the application of the review, as it is required in $\mathrm{SQF}$, is not effective. Periodic review that the operational practices (reality) meet the intended practices (standard) would prevent the root cause of recalls. The review 
activity could be a quarterly requirement or, depending on the production schedule, a preoperational validation activity completed prior to each production run.

\subsubsection{Case Study: Reviewing Ingredient Formulations}

In a release from Pepperidge Farm, the Norwalk, Connecticut based company notified the public that several varieties of bagels produced within the same week were being recalled for undeclared presence of almond and peanut allergen. The allergens were not intended to be in the formula and were determined to be included in an ingredient (US Food and Drug Administration, 2015a). According to the SQFI database this organization is SQF Level 3 certified.

The exact reason an ingredient was found to contain unexpected peanuts and almonds is not clear in the report, however there is one activity that could prevent the mistake regardless of the cause. At the time of formulating the finished product, and possibly at subsequent reformulations, management compiled a finished product ingredient statement based on the ingredient statements of the materials sourced. Via an ingredient formulation change by the vendor, a change in vendor, or an emergency substitution of a similar type of ingredient on hand, the material used for that specific production date was different from the normally sourced material. Similar to the previous case, the management activity needed to prevent the root cause of the recall was done after the food was shipped instead of earlier in the process, when the changed material was sourced or when it arrived in receiving. 


\subsubsection{Harmonious Organizational Hierarchy}

The organizational hierarchies within a food manufacturing system can vary but will generally follow a structure of company $>$ business unit $>$ department $>$ team $>$ role. Within an individual's role is a set of tasks that are done on some regular basis which reflect the individual's performance. In the operations business unit, the Production department does the food producing, the Maintenance department supports the equipment used for food producing, and the Quality department supports the use and creation of key information regarding the process. Referring back to Figure 3, the model of a food manufacturing system per the SQF code, we see that there is a core, material flow process of transforming ingredients into finished goods. The other output from the system is information in the form of validated procedures and verified records. Even though these two activities are associated with the same process steps, they are carried out by different roles which report through different teams and departments in the organization. The result is an organization with coworkers in roles that interact on the same process (food production) but have conflicting goals due to their reporting structure through different teams. This creates a conflict of goals, with individuals working against each other instead of working together, in the direction of the company vision and within the company culture.

\section{The Missing Step: An Organizational Culture of Food Safety}

The SQF code only covers cultural aspects of the facility by requiring a written and posted statement of support from management, food safety training, and role definition. The component that is left out of SQF is the organizational culture. This is 
understandable due to the nature of a code which is used to evaluate an operation - it is difficult to evaluate an organization's culture during a single site visit, without doing employee and management surveys (Hofstede, Neuijen, Ohayv, \& Sanders, 1990). The food manufacturing system is a complex organizational structure with multiple hierarchies that can produce roles, teams, and departments which contradict one another. Take for example, Employee 1 and Employee 2 in Table 2.

Table 2. Examples of roles with different organizing principles

\section{Level of Hierarchy Employee $1 \quad$ Employee 2}

\section{Employee 3}

\begin{tabular}{llll}
\hline Business Unit & Operations & Operations & Corporate \\
\hline Department & Production & Quality \& Tech Services & Finance \\
\hline Team & Preparation & Quality & A/P \\
\hline Role & Mixer Operator & Lab Technician & Clerk
\end{tabular}

Employee 1 is a classic throughput-focused role, regardless of having the same level of food safety training as Employee 2, a classically information-focused role. If the correct information is not used or generated by the process Employee 1 is tasked with, Employee 2 may not be able to monitor and create records. Additionally, for Employee 1 to use or generate information may distract from her team's focus on improved/consistent material throughput. This means that Employee 2 cannot do his or her job if Employee 1 does not participate in these activities that detract from his or her team goal.

\section{Recommendation: Evaluating the Organization for Food Safety Culture}

Individuals with conflicting roles need to know that they are working toward the same goal. This will not happen without a solid umbrella vision at the business unit level or 
higher (Schultz, 2014). There is evidence, provided by Powell, Jacob, \& Chapman, of at least three specific food borne illness outbreaks at facilities that did not have a cohesive food safety culture (2011). When employees were surveyed, cultures of "making and saving money," low urgency reacting to food safety hazards, and low quality ingredients and wages resulted in falsification of records, HACCP plans without validated bacterial kill steps, and disregard for facility hygiene.

Leaders of food manufacturing organizations, which are hierarchical socio-cultural systems, must not fall into the trap of thinking that the vision, or organizing principle, of senior management is actually reflected in the actions of the organization at all levels. Armstrong suggests that looking at the integrated relationships between employees in different departments, and at different levels, is a key indicator of whether the corporate vision is actually disseminated and indicative of the corporate food safety culture (1999). Key recommendations are that the senior-most executive should communicate food safety initiatives, and that the team level in an operations department is where responsibility for food safety should lie, not with a detached team that is rooted in a different department focused on processing accurate information. Ultimately, if the organizing principle of a food manufacturing system is centered on cutting costs and making sales, food safety will be considered an external constraint on the organization, even if a food safety culture is attempted with front line employees. An external organizing principle will never shift the focus of a conflicting internal organizing principle, unless the roles are reversed and food safety is internalized in the department responsible for handling materials and making food. 
4.2.3.1 Case Study: Creating a Culture of Caution and Care in Allergen Handling In a press release from WhiteWave Foods on February 20, 2015, the Broomfield, Colorado based company notified the public that a cheddar sandwich cracker product actually contained a peanut butter sandwich cracker. The producer accidentally packed the peanut containing product in the wrong packaging (US Food and Drug Administration, 2015c). According to the SQFI database, this organization is SQF Level 2 certified.

Food manufacturing facilities, regardless of the level of mechanical automation, are run by people. The organization employs production and quality personnel to ensure consistent, compliant, and safe products are made. For the wrong packaging to be used in a product containing a possibly life-threatening allergen, the organization failed at their goal. A warehouse person brought the packaging material to production. A production employee loaded the packaging into production equipment. A quality employee verified the packaged finished product met the product standard. Mistakes do happen but food manufacturing organizations diligently establish procedures and policies to prevent systemic failures. The organization's senior management team is ultimately at fault in this case for not creating the policies and programs to support the creation of a compliant, safe product. Merely requiring training and a clear job description does not address the involvement of an organization's culture in its ability to consistently produce safe foods. 


\section{DISCUSSION AND CONCLUSION}

\subsection{Discussion}

The purpose of this research was to evaluate a model of the food manufacturing system based upon a popular third-party food safety assessment, with the goal to make structural changes that would reduce the incidence of allergen-related recalls. The results suggest several improvements of the food manufacturing system over the SQF-based model. The recommendations would reduce the number of undeclared allergen recalls due to putting a product in the wrong packaging, having incorrect information on the intended packaging, and using ingredients that have not been evaluated against the finished product ingredient statement. Though the Safe Quality Food Institute employs academic and industry experts, it appears that a third viewpoint would be beneficial - the systems perspective. Without a complete view of the system, an organization could not effectively problem-solve, create policies, or improve the food manufacturing system they are charged with managing. The perspective of practitioners trained in systems methodologies could create a food safety management system with improved information feedback, which food manufacturing managers could employ to safeguard against biological, physical, and chemical hazards in their products. While the resulting recommendations of this thesis may not be necessary for every food manufacturer, they show how an industry standard food safety code can do more to prescribe managerial activities that support an effective food manufacturing system. 


\subsection{Limitations}

There are two other likely causes for allergen recall that are not addressed with this systems analysis because the elements involved are not entirely within the scope of the food manufacturing system model based on the SQF code. These are the less likely causes but they are worth covering to show the limitation of the SQF code to touch on each route of undeclared allergen in the marketplace.

The fourth most likely cause of allergen recall summarized by the Gendel et. al. review is cross-contact between ingredients or equipment (2014). This would be due to employee mishandling of ingredients or inadequate sanitation of equipment used for both allergencontaining and non-allergen-containing products. These are straight forward reasons for allergen contamination that should not occur with good employee practices (i.e. separate scoops for weighing each allergenic ingredient) or good sanitation verification (i.e. visual and chemical review of equipment cleanliness). Though these mistakes may be more likely in the type of company that could benefit from the third recommendation of creating a culture of food safety, these are considered foundational, prerequisite programs in HACCP and are well covered in the SQF code (Panisello \& Quantick, 2001; Food Marketing Institute, 2013).

The fifth most likely cause for recall in the Gendel et. al. review is undeclared allergen in an ingredient (2014). This may be accidental or intentional, criminal adulteration. The example of peanut allergen in cumin from the introduction section of this thesis illustrates the risk related to unlabeled allergens, though it is more complex than just a food safety issue of accidental contamination, as it is the unintended result of criminal, intentional 
adulteration by a supplier to make their product more profitable. The cumin manufacturer adulterated with a cheaper, unlabeled ingredient to stretch the production volume larger than the small cumin harvest would have supported. Vendor approval is an important topic in the food industry, especially with the amount of imported foods in the global trade environment (Taylor et al., 2006). It is a complex issue that heavily relies on the relationships and information flows between the manufacturer and elements external to the food manufacturing system such as vendors, governmental regulations, and customers (for information feedback).

\subsection{Future Research}

Although the research findings address real concerns in food safety management, there are limitations to the material presented in this thesis. Firstly, the recommendations need to be validated in real organizations. Building upon the anecdotal evidence presented here from US food recall records, implementing the research recommendations in an organization would show the validity and effectiveness of such interventions.

Additionally, and more specifically, the third recommendation of creating a more robust culture of food safety is more abstract than an audit could evaluate. Auditors are on site for one to four days, depending on the size of the business. This allows very little time to observe the activities that would provide insight into the organizational culture or to survey employees and determine the perspective of employees directly responsible for production and monitoring activities. A new method of evaluating culture would have to be implemented by auditors to effectively use this concept as an indicator of food safety risk, which would require the development of a qualitative assessment. 


\subsection{Conclusion}

Despite regulatory and industry initiatives to reduce the number of unsafe foods in the market, unlabeled allergens create the largest cause for product recall and the largest cause for self-reporting in the FDA's Reportable Foods Registry. The responsibility to keep contaminants out of finished products lies with the consumer product manufacturer, regardless of whether that manufacturer created the root cause or the contamination happened earlier in the supply chain. The SQF code, meeting the GFSI standard for food safety, covers the complex activities within a food manufacturing system that can result in a food hazard, as well as the programs that can control for a hazard if it gets into the food supply. In practice, the SQF code should make better use of control theory to reduce delays in production monitoring activities, should make better use of purposeful action in the implementation of a HACCP plan to ensure continuing validity of the plan, and SQFI needs to consider adding an organizational assessment for food safety culture. 


\section{REFERENCES}

Aguayo, R. (1991). Dr. Deming: The American who taught the Japanese about quality. Simon and Schuster. Retrieved from http://books.google.com.proxy.lib.pdx.edu/books?hl=en\&lr=\&id=834YItvV9CIC \&oi=fnd\&pg $=$ PR7\&dq $=$ deming + toyota\&ots $=$ p102d55xdQ\&sig $=$ Y8v9xPQf181fjE VV2_36DgEnDxk

Armstrong, G. D. (1999). Towards integrated hygiene and food safety management systems: the Hygieneomic approach. International Journal of Food Microbiology, 50(1-2), 19-24. http://doi.org/10.1016/S0168-1605(99)00073-2

Bauman, H. E. (1995). The origin and concept of HACCP. In A. M. Pearson \& T. R. Dutson (Eds.), HACCP in Meat, Poultry, and Fish Processing (pp. 1-7). Springer US. Retrieved from http://link.springer.com.proxy.lib.pdx.edu/chapter/10.1007/978-1-4615-2149-5_1

Bennett, J. G. (1966). The Dramatic Universe (Vol. 3). London: Hodder \& Stoughton. Branum, A. M., \& Lukacs, S. L. (2009). Food Allergy Among Children in the United States. Pediatrics, 124(6), 1549-1555. http://doi.org/10.1542/peds.2009-1210

CDC - Food Safety Office - Food Safety. (2014, March 5). Retrieved March 5, 2014, from http://www.cdc.gov/foodsafety/food-safety-office.html

CDC Vital Signs. (2014). Retrieved March 6, 2014, from http://www.cdc.gov/vitalsigns/index.html

Center for Food Safety and Applied Nutrition. (2015, February 21). Safety Alerts \& Advisories - FDA Consumer Advice on Products Containing Ground Cumin with Undeclared Peanuts [WebContent]. Retrieved February 21, 2015, from http://www.fda.gov/food/recallsoutbreaksemergencies/safetyalertsadvisories/ucm 434274.Htm

Cucu, T., Jacxsens, L., \& De Meulenaer, B. (2013). Analysis To Support Allergen Risk Management: Which Way To Go? Journal of Agricultural and Food Chemistry, 61(24), 5624-5633. http://doi.org/10.1021/jf303337z

e-CFR: Title 21: Food and Drugs, Title 21: Food and Drugs Electronic Code of Federal Regulations § Part 120-Hazard Analysis and Critical Control Point (haccp) Systems. Retrieved from http://www.ecfr.gov/cgibin/retrieveECFR?gp=1\&SID=d0690509abf3f5d78a1c631bac15144c\&ty=HTML $\& \mathrm{~h}=\mathrm{L} \& \mathrm{n}=21 \mathrm{y} 2 \cdot 0.1 \cdot 1.17 \& \mathrm{r}=\mathrm{PART}$

FDA Won't Set Specific FSMA Deadlines Despite Court Order. (2014, February 26). Retrieved February 13, 2015, from http://www.foodsafetynews.com/2013/06/fdawont-set-specific-fsma-deadlines-despite-court-order/

Flood, R. L., \& Jackson, M. C. (1991). Total Systems Intervention: A Practical Face to Critical Systems Thinking. Systems Practice, 4(3), 191-213.

Flynn, D. (2014, September 19). Jury Verdicts: Guilty, Guilty, and Guilty in PCA Criminal Trial. Retrieved February 9, 2015, from http://www.foodsafetynews.com/2014/09/guilty-guilty-and-guilty-in-pcacriminal-trial-in-albany-ga/ 
Food Allergy Research and Resource Program | University of Nebraska-Lincoln. (2015, January 26). Retrieved February 13, 2015, from https://farrp.unl.edu/reg-sit-usa

Food Marketing Institute. (2013, May). The SQF Code, Edition 7. Food Marketying Institute. Retrieved from http://www.sqfi.com/wp-content/uploads/SQF-Code-Ed7.1-4-29-13.pdf

Fulponi, L. (2006). Private voluntary standards in the food system: The perspective of major food retailers in OECD countries. Food Policy, 31(1), 1-13. http://doi.org/10.1016/j.foodpol.2005.06.006

Gendel, S. M. (2013). The Regulatory Challenge of Food Allergens. Journal of Agricultural and Food Chemistry, 61(24), 5634-5637. http://doi.org/10.1021/jf302539a

Gendel, S. M., Zhu, J., Nolan, N., \& Gombas, K. (2014). Learning from FDA Food Allergen Recalls and Reportable Foods. Food Safety Magazine, (April/May 2014). Retrieved from http://www.foodsafetymagazine.com/magazinearchive1/aprilmay-2014/learning-from-fda-food-allergen-recalls-and-reportablefoods/

Glenn, S. S., \& Malott, M. E. (2006). Complexity and selection: Implications for organizational change. Behavior and Social Issues, 13(2), 89-106.

Grant, E. L., \& Leavenworth, R. S. (1980). Statistical quality control. New York: McGraw-Hill.

Hofstede, G., Neuijen, B., Ohayv, D. D., \& Sanders, G. (1990). Measuring Organizational Cultures: A Qualitative and Quantitative Study Across Twenty Cases. Administrative Science Quarterly, 35(2), 286-316. http://doi.org/10.2307/2393392

Hourihane, J. O., Kilburn, S. A., Dean, P., \& Warner, J. O. (1997). Clinical characteristics of peanut allergy. Clinical \& Experimental Allergy, 27(6), 634639. http://doi.org/10.1111/j.1365-2222.1997.tb01190.x

Juice - Guidance for Industry: Juice HACCP Hazards and Controls Guidance First Edition; Final Guidance. (2004, February). [WebContent]. Retrieved March 7, 2014, from http://www.fda.gov/Food/GuidanceRegulation/GuidanceDocumentsRegulatoryInf ormation/Juice/ucm072557.htm\#ftn1

Kauffman, S. (1995). At Home in the Universe: The Search for the Laws of SelfOrganization and Complexity. Oxford University Press, USA.

Lane, D. C., \& Oliva, R. (1998). The greater whole: Towards a synthesis of system dynamics and soft systems methodology. European Journal of Operational Research, 107(1), 214-235. http://doi.org/10.1016/S0377-2217(97)00205-1

Luning, P. A., \& Marcelis, W. J. (2007). A conceptual model of food quality management functions based on a techno-managerial approach. Trends in Food Science \& Technology, 18(3), 159-166. http://doi.org/10.1016/j.tifs.2006.10.021

Luning, P. A., Marcelis, W. J., Rovira, J., Van der Spiegel, M., Uyttendaele, M., \& Jacxsens, L. (2009). Systematic assessment of core assurance activities in a company specific food safety management system. Trends in Food Science \& Technology, 20(6-7), 300-312. http://doi.org/10.1016/j.tifs.2009.03.003 
Manzini, R., \& Accorsi, R. (2013). The new conceptual framework for food supply chain assessment. Journal of Food Engineering, 115(2), 251-263. http://doi.org/10.1016/j.jfoodeng.2012.10.026

Milios, K., Zoiopoulos, P. E., Pantouvakis, A., Mataragas, M., \& Drosinos, E. H. (2013). Techno-managerial factors related to food safety management system in food businesses. British Food Journal, 115(9), 1381-1399.

Panisello, P. J., \& Quantick, P. C. (2001). Technical barriers to Hazard Analysis Critical Control Point (HACCP). Food Control, 12(3), 165-173. http://doi.org/10.1016/S0956-7135(00)00035-9

Parsons, T. (1966). Societies: evolutionary and comparative perspectives. Elglewood Cliffs New Jersey: Prentice-Hall.

Parsons, T. (1971). The Systems of Modern Societies. Englewood Cliffs New Jersey: Prentice-Hall.

Petkov, D., Petkova, O., Andrew, T., \& Nepal, T. (2007). Mixing Multiple Criteria Decision Making with soft systems thinking techniques for decision support in complex situations. Decision Support Systems, 43(4), 1615-1629. http://doi.org/10.1016/j.dss.2006.03.006

Pothukuchi, K. (2000). The Food System: A Stranger to the Planning Field. (cover story). Journal of the American Planning Association, 66(2), 113.

Powell, D. A., Erdozain, S., Dodd, C., Costa, R., Morley, K., \& Chapman, B. J. (2013). Audits and inspections are never enough: A critique to enhance food safety. Food Control, 30(2), 686-691.

Powell, D. A., Jacob, C. J., \& Chapman, B. J. (2011). Enhancing food safety culture to reduce rates of foodborne illness. Food Control, 22(6), 817-822.

Rother, M. (2010). Toyota kata: Managing people for improvement, adaptiveness, and superior results. McGraw Hill New York, NY.

Scallan, E., Hoekstra, R. M., Angulo, F. J., Tauxe, R. V., Widdowson, M.-A., Roy, S. L., ... Griffin, P. M. (2011). Foodborne Illness Acquired in the United States-Major Pathogens. Emerging Infectious Diseases, 17(1), 7-15. http://doi.org/10.3201/eid1701.P11101

Schneider, M., \& Somers, M. (2006). Organizations as complex adaptive systems: Implications of Complexity Theory for leadership research. The Leadership Quarterly, 17(4), 351-365. http://doi.org/10.1016/j.leaqua.2006.04.006

Schultz, J. R. (2014). Framing the Organization's Purpose With Its Ultimate Goals in Mind. Global Business and Organizational Excellence, 33(3), 46-55. http://doi.org/10.1002/joe.21543

Sicherer, S. H., Muñoz-Furlong, A., Godbold, J. H., \& Sampson, H. A. (2010). US prevalence of self-reported peanut, tree nut, and sesame allergy: 11-year followup. Journal of Allergy and Clinical Immunology, 125(6), 1322-1326. http://doi.org/10.1016/j.jaci.2010.03.029

Skees, J. R., Botts, A., \& Zeuli, K. A. (2001). The potential for recall insurance to improve food safety. The International Food and Agribusiness Management Review, 4(1), 99-111. http://doi.org/10.1016/S1096-7508(01)00072-6 
Sobal, J., Kettel Khan, L., \& Bisogni, C. (1998). A conceptual model of the food and nutrition system. Social Science \& Medicine, 47(7), 853-863.

http://doi.org/10.1016/S0277-9536(98)00104-X

SQFI Reliance. (2015). Public Search (New) [Database]. Retrieved March 8, 2015, from https://sqf.etq.com/production/reliance?ETQ\$CMD=CMD_EXECUTE_ACTION FORMULA\&ETQ\$ACTION_NAME=SEARCH_1\&ETQ\$APPLICATION_N $\overline{A M E}=\mathrm{COMPANY} 1 \& E T Q \$ \overline{F O R M}$ _NAME$=$ PUBLIC_SEARCH\&ETQ\$KEY NAME$=$ PUBLIC_SEARCH_ID\&ETQ\$KEY_VALUE $=1917390159 \&$ undefined \&ETQ\$SCREEN_WIDTH $=\overline{1} 366$

Taiwo, J. (2001). Systems approaches to total quality management. Total Quality Management, 12(7-8), 967-973. http://doi.org/10.1080/09544120100000022

Taylor, S. L., Hefle, S. L., Farnum, K., Rizk, S. W., Yeung, J., Barnett, M. E., ... Bryant, C. M. (2006). Analysis and Evaluation of Food Manufacturing Practices Used to Address Allergen Concerns. Comprehensive Reviews in Food Science and Food Safety, 5(4), 138-157. http://doi.org/10.1111/j.1541-4337.2006.00012.x

US Food and Drug Administration. (2014). The Reportable Food Registry: Targeting Inspection Resources and Identifying Patterns of Adulteration (p. 12). Retrieved from http://www.fda.gov/downloads/Food/ComplianceEnforcement/RFR/UCM395684 .pdf

US Food and Drug Administration. (2015a). Pepperidge Farm Issues Voluntary Recall of Bagels in Select States Due to Undeclared Allergens [Press Release] (WebContent). Retrieved from http://www.fda.gov/Safety/Recalls/ucm433775.htm

US Food and Drug Administration. (2015b). Tarrier Foods Issues Allergy Alert on Undeclared Peanuts and Egg in Chopped Twix [Press Release] (WebContent). Retrieved from http://www.fda.gov/Safety/Recalls/ucm431081.htm

US Food and Drug Administration. (2015c). WhiteWave Foods Voluntarily Recalls Horizon Cheddar Sandwich Crackers [Press Release] (WebContent). Retrieved from http://www.fda.gov/Safety/Recalls/ucm435172.htm

Valder, P. (2009). GFSI Food Safety Standards. Quality Digest, 29(4), 20-23.

Van der Spiegel, M., Luning, P. A., Ziggers, G. W., \& Jongen, W. M. F. (2003). Towards a conceptual model to measure effectiveness of food quality systems. Trends in Food Science \& Technology, 14(10), 424-431. http://doi.org/10.1016/S09242244(03)00058-X

Weise, E. (2012, October 5). Peanut butter plant tests positive for salmonella. USA Today. Retrieved from http://www.usatoday.com/story/news/nation/2012/10/05/peanut-buttersalmonella-outbreak/1615475/ 